\title{
The Effects of Early Feeding of Moringa Oleifera Leaf Meal on Performance of Broiler and Pullet Chicks
}

\author{
Oludoyi, I.A. and *Toye, A.A. \\ Department of Animal Production, Faculty of Agriculture, University of llorin, Kwara State, Nigeria. \\ *Corresponding Author: ayo.toye@btinternet.com
}

\begin{abstract}
The effects of early feeding of Moringa Oleifera Leaf Meal (MOLM) on performance from 07 weeks age was examined in broiler (Hubbard breed) and pullet (Bovans Nera black rock breed) chicks. Within each breed, 8 birds were randomly assigned to each of 3 treatment groups and each group was fed only one of 3 diets (0\% MOLM, 5\% MOLM, 10\% MOLM) from 04 weeks age. All birds were fed with a standard diet (containing no MOLM) from 47 weeks age. Body weight, linear growth (Body length and girth; wing, thigh, drumstick, and shank length) and Body Mass Index (BMl; a surrogate measure of obesity) were measured at age 1, 4 and 7 weeks. At week 4, a significant $(P<0.05)$ difference in bodyweight was observed between broiler groups ( $0 \%$ MOLM, $10 \%$ MOLM $>5 \%$ MOLM), whereas no significant difference in body weight was observed between pullet groups. At week 7 ( 3 weeks following discontinuation of MOLM diets), broilers in $0 \%$ MOLM dietary group had significantly $(P<0.05)$ higher body weight ( $0 \%$ MOLM $>5 \%$ MOLM, 10\% MOLM), and a similar trend was observed for body length and drumstick length. Also in broilers, BMI was significantly $(p<0.05)$ higher in 5\% MOLM than other groups but thigh length was not significantly different between groups. In contrast to broilers, no significant difference in body weight or any of the other parameters measured was observed between pullet groups at 7 weeks age.

The experiment showed that whereas the inclusion of MOLM in the diet of broilers from 0-4 weeks suppressed performance (relative to 0\% MOLM) at age 4 weeks and thereafter, no effect on performance of pullets at age 4 and 7 weeks was observed when moringa was fed for the same duration, thus highlighting differential adaptation of chicks from different genetic backgrounds (meat vs. egg type breeds) to MOLM. The use of MOLM at $=10 \%$ inclusion in the diet of pullets should be encouraged as it yields comparable performance to conventional ingredients, and its weight limiting effects in broilers may be harnessed for nutritional management of broiler-breeder bodyweight which is essential for maximising their reproductive performance.
\end{abstract}

Keywords: Moringa Oleifera Leaf Meal, Growth Performance, Broiler, Pullet.

\section{INTRODUCTION}

Poultry products such as meat and eggs have assumed the role of providing much needed animal protein to mankind (Aihonsu and Sunmola, 1999). Poultries are characterized by the best biological efficiency of nutrient transformation into quality animal protein (Oluwafemi, 2009). However, the monetary cost of this transformation is very high (Szebiotko, 1981). The quest for least cost formulation has led animal nutritionists to investigate the nutritional potential of non-conventional ingredients for compounding animal 
rations and to identify the level of the inclusion of such ingredients that could produce satisfactory performance (Oluwafemi, 2009).

Non-conventional ingredients such as palm kernel cake had been used to feed monogastric animals; A study was carried out by Oluwafemi (2009) on the utilization of palm kernel cake in monogastric animal feeding as a replacement for maize. Although, there is variability in the nutritional composition, there exists great potential for producing good quality meat from palm kernel cake because the product is inexpensive, readily available and has a low cost of processing.

In the tradition of exploring utility of non-conventional feedstuffs for use in poultry feed formulation, this study sought to examine Moringa Oleifera Leaf Meal as a non-conventional ingredient for use in feeding broilers and pullet in their early stage of life, at which nutrition is crucial for actualising longer term development potential.

Moringa Oleifera is a multipurpose tree which could substitute Leucaena leucocephala as it possesses beneficial characteristics as multipurpose tree species (Kakengi et al., 2007). The leaves and green pods are used as vegetables by humans and are rich in carotene and ascorbic acid with a good profile of amino acids (Makkar and Becker, 1996).

Moringa Oleifera Leaf Meal (MOLM) contains 28.0\% Crude Protein, 2.5\% Calcium (Olugbemi et al., 2010a), and 2,978 kcal/kg (Olugbemi et al., 2010b). It has low levels of anti-nutritional factors (Makkar and Becker, 1997), and can therefore serve as a valuable non-conventional feedstuff in poultry feeds and if grown in quantities that are sufficient to lower the cost of animal feeds can reduce the pressure on other feedstuffs in the conventional repertoire.

\section{MATERIALS AND METHODS}

All animal experiments were carried out in accordance with Institutional guidelines on the humane care and use of animals in research and experimentation.

\section{Experimental Site}

The experiment was carried out in the Animal Pavilion of the Animal Production Department, Faculty of Agriculture, University of Ilorin.

\section{Sources of Moringa Oleifera LeafMeal (MOLM) and Experimental Birds}

MOLM was sourced from Tasha, Kaduna and llorin Metropolis. Day-old-broilers and pullet chicks (Hubbard and Bovans Nera Black Breeds respectively) were purchased from Yammfy Farms, llemona in Kwara State, Nigeria.

\section{Experimental Birds}

A total of 48 chickens were used for the experiment comprising 24 Hubbard broilers and 24 Nera Black pullet chicks. Day-old chicks were randomly assigned to three dietary treatments containing MOLM at 0, 5 and $10 \%$ supplementary levels respectively i.e. for broilers fed $5 \%$ MOLM diet, the birds must consume $5 \mathrm{~g}$ Moringa leaf meal for every $95 \mathrm{~g}$ of broiler starter diet consumed etc. There were 8 birds per treatment group per breed, and each group was fed a different diet for four weeks. Subsequently, all birds were fed with a standard diet to 7 weeks age. 
Oludoyi \& Toye

\section{Body Weight and Linear Measurements}

Body Weight (BW): Body weight in gram (g) units recorder to two decimal places, was taken by use of a sensitive weighing scale (Scout II).

Body Length (BL): Body length was taken as the nostril to pygostyle distance measured in centimetre $(\mathrm{cm})$ units when a tape measure is stretched from a bird's nasal opening, along its gently stretched neck, and along its back, to the tip of its pygostyle.

Body Girth (BG): Body girth was taken as the distance in centimetre $(\mathrm{cm})$ units covered when a tape measure is looped round the region of the breast, taking care to run the tape under (rather than over) the wing.

Shank Length (SL): The shank length was taken as the distance in centimetres $(\mathrm{cm})$ between the foot pad and the hock joint, measured by use of a set of Venire callipers.

Thigh Length (TL): Thigh length was taken as the distance between the tip of the tarsus and the ball joint, measured in centimetre $(\mathrm{cm})$ units by use of a tape measure.

Wing Length (WL): Wing length was taken as the distance from the humerus-coracoid junction to the distal tip of the phalange digits, and was measured in centimetre $(\mathrm{cm})$ units by use of a tape measure.

Growth Rate: For body weight ( $\mathrm{g}$ ), and each of the linear measures of body growth recorded (cm), Growth rate/velocity/potential for 1, 3 and 6 successive week periods were determined by use of an adapted version of the formula of Maciejowski and Ziêba (1982),

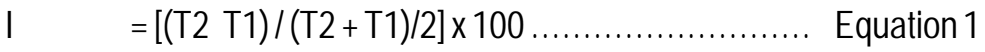

Where:

I = Growth rate per unit period (\%).

T1 =Average initial reading for the stated period $(\mathrm{g}$ or $\mathrm{cm})$

T2 =Average final reading for the stated period $(\mathrm{g}$ or $\mathrm{cm})$

\section{Body Mass index (BMI)}

The body mass index was derived by dividing body weight expressed in gram units by the square of body length expressed in cm units.

\section{Chemical Analysis}

The proximate analysis of the experimental diets was carried out using the procedure outlined by the Association of Official Analytical Chemists (A.O.A.C., 1990).

\section{Statistical Analysis}

Least squares means and standard error values for each treatment group were determined by the use of Microsoft Office Excel 2007 (Microsoft Corp.), and all data were further subjected to Analysis of Variance by the use of SPSS Version 17 (IBM, SPSS). Significantly different means $(P<0.05)$ were separated by the use of the Duncan's Multiple Range Procedure option in SPSS. 


\section{RESULTS}

Table 1 shows the chemical composition of the dietary treatments which were $0 \%$ MOLM, 5\% MOLM, and $10 \%$ MOLM. The percentage content of crude protein, ash ether extract and crude fibre increased as the MOLM inclusion level in the diet increased. The moisture content and dry matter of Diet $\mathrm{A}(0 \%)$ and $\mathrm{C}(10 \%)$ were similar. Diet B (5\%) had the lowest moisture content and dry matter.

\section{Effect of MOLM on Body Weight, Body Weight Rate and Body Mass Index (BMI) of Broilers (Hubbard Breed)}

Table 2 shows the body weight, body weight (growth) rate, and Body Mass Index (BMI) of broiler chickens fed graded levels of MOLM. At week 1 , body weight of broilers fed the control diet ( $0 \%$ MOLM) was significantly $(p<0.05)$ higher than the body weight of broilers fed $5 \%$ MOLM; the body weights of broilers in the $10 \%$ MOLM dietary group was intermediate between, but not significantly different from either. The highest body weight was recorded in broilers fed $0 \%$ MOLM while the lowest body weight was recorded in broilers fed the $5 \%$ MOLM. Body weight of broilers fed $5 \%$ MOLM was significantly $(p<0.05)$ lower than observed for other groups at week 4 (0\% MOLM, 10\% MOLM $>5 \%$ MOLM). At week 7 , there was no significant difference $(p>0.05)$ in the body weight of broilers that were initially fed $5 \%$ MOLM and $10 \%$ MOLM from week $0-4$, and both weighed significantly $(p<0.05)$ less than the $0 \%$ MOLM group at the same age. The body weight rate of broilers fed $5 \%$ MOLM was lowest $(p<0.05)$ from week 1 to $4(0 \%$ MOLM, 10\% MOLM $>5 \%$ MOLM). At week 4 to 7 , the body weight rate of broilers fed $5 \%$ MOLM (from week 0 to 4 weeks age) was significantly higher $(p<0.05)$ than broilers in the $10 \%$ MOLM dietary group; the body weight rate of broilers in 0\% MOLM was not significantly different from either. The Weeks 17 body weight rate of broilers in $0 \%$ MOLM dietary group was significantly $(p<0.05)$ higher than broilers in the $10 \%$ MOLM dietary group. Body Mass Index (BMI) was not significantly different ( $p>0.05$ ) between groups at week 1 . At week 4 , the BMI of broilers in the $0 \%$ MOLM dietary group was significantly higher $(p<0.05)$ than those in the $5 \%$ MOLM dietary group; BMI of broilers in 10\% MOLM dietary group was not significantly different from either. The BMI of broilers in the $5 \%$ MOLM dietary group was significantly $(p<0.05)$ higher at age 7 weeks ( $5 \%$ MOLM $>0 \%$ MOLM, $10 \%$ MOLM).

\section{Effect of MOLM on Body Weight of Pullets (Bovans Nera Breed)}

Table 3 shows the body weights, body weight rates and Body Mass Index (BMI) of pullets fed graded levels of MOLM. At week 1 , the pullets fed $0 \%$ MOLM had significantly $(p<0.05)$ higher body weight than other groups. No significant $(p>0.05)$ difference was observed in the body weights of pullets in the three dietary treatment groups (0\%MOLM, 5\% MOLM, and 10\% MOLM) at week 4 and 7. Between Weeks 1 4, 4- 7 and overall (weeks 17 ), there was no significant difference $(p>0.05)$ in the body weight rate of pullets in the three dietary groups. At week 1 and 4, the BMI of pullets in the 10\% MOLM dietary group was significantly higher $(p<0.05)$ than observed for other groups ( $0 \%$ MOLM and $5 \%$ MOLM). The BMI was not significantly $(p>0.05)$ different between the dietary groups at age 7 weeks. 


\section{Effect of MOLM on Linear Growth of Broilers (Hubbard Breed)}

Table 4 shows the linear growth measurements (body length and girth, shank length, thigh length and drumstick length) of broilers fed graded levels of MOLM. No significant ( $p>0.05)$ difference existed in the body length of broilers in the three dietary groups at week 1 . Body length of broilers fed $0 \%$ MOLM was significantly higher than observed for other groups ( $p<0.05$ ), while broilers fed $5 \%$ MOLM had the lowest body length at week 4 . At week 7 , the body length of broilers fed $0 \%$ MOLM was significantly higher than observed for other groups $(p<0.05)$, while there was no significant difference $(p>0.05)$ observed in body length of broilers fed $5 \%$ MOLM and 10\% MOLM respectively. No significant difference existed in Body Girth between the three dietary groups (0\% MOLM, 5\% MOLM, and 10\% MOLM) at week 1. At 4 week age, body girth of broilers fed $0 \%$ MOLM was significantly $(p<0.05)$ higher than those fed $5 \%$ MOLM; body girth of broilers in 10\% MOLM dietary group was not significantly different from either. The body girth of broilers in the $0 \%$ MOLM dietary group was highest $(p<0.05)$ at 7 week age $(0 \%$ MOLM $>10 \%$ MOLM $>5 \%$ MOLM). At week 1 , shank length was not significantly $(p>0.05)$ different between the three dietary groups. The shank length of broilers in the $0 \%$ MOLM dietary group was significantly $(p<0.05)$ higher than observed for other groups at week $4(0 \%$ MOLM > 5\% MOLM, 10\% MOLM). The shank length of broilers in the $0 \%$ MOLM dietary group was significantly higher $(p<0.05)$ than those in the $5 \%$ MOLM dietary group at 7 weeks age. The shank length of broilers in the $10 \%$ MOLM dietary group was not significantly different from either. At week 1, the thigh length of broilers in the 5\% MOLM dietary group was significantly higher $(p<0.05)$ than broilers in the $10 \%$ MOLM dietary group, however thigh length of broilers in the $0 \%$ MOLM dietary group was not significantly different from either. The thigh length of broilers in the $0 \% \mathrm{MOLM}$ dietary group was significantly higher $(p<0.05)$ than observed for other groups at age 4 week $(0 \%$ MOLM $>5 \%$ MOLM, 10\% MOLM). The thigh length was not significantly ( $p>0.05)$ different between dietary groups at age 7 weeks. At week 1 , the drumstick length was not significantly $(p>0.05)$ different between the dietary groups. The drumstick length of broilers in the $0 \%$ MOLM dietary group was significantly $(p<0.05)$ higher than observed for other groups at week 4 and 7 ( $0 \%$ MOLM > 5\% MOLM, 10\% MOLM).

\section{Effect of MOLM on Linear Growth of Pullets (Bovans Nera Breed)}

Table 5 shows the linear growth measurements (body length and girth, shank length, thigh length and drumstick length). Pullets fed $0 \%$ MOLM had significantly $(p<0.05)$, higher body length than other groups, and the lowest was observed in pullets fed 10\% MOLM at week 1, whereas body girth of pullets fed $5 \%$ MOLM was not significantly different from either. The body length of pullets fed $10 \%$ MOLM was significantly $(p<0.05)$ lower than observed for other genotype-matched groups at age 4 week ( $0 \%$ MOLM, $5 \%$ MOLM $>10 \%$ MOLM). At week 7 , there was no significant difference $(p>0.05)$ in the body length of pullets in the three dietary groups ( $0 \%$ MOLM, $5 \%$ MOLM, 10\% MOLM respectively). The body girth of pullets in the $0 \%$ MOLM dietary group was significantly $(p<0.05)$ higher than pullets in the $10 \%$ MOLM dietary group at week 1 while the body girth of pullets in the $5 \%$ MOLM dietary group was not significantly 
different from either. The body girth of pullets in the 5\% MOLM dietary group was significantly higher at 4 week age ( $5 \%$ MOLM > $\%$ MOLM, 10\% MOLM). At week 7 , the body girth was not significantly $(p>0.05)$ different between the dietary groups. At 1 week age, the shank length of pullets in the 5\% MOLM dietary group was significantly $(p<0.05)$ higher than observed for pullets in $10 \%$ MOLM dietary group while the shank length of pullets in $0 \%$ MOLM dietary group was not significantly different from either. The shank length of pullets in $5 \%$ MOLM dietary group was significantly $(p<0.05)$ higher at 4 week age $(5 \%$ MOLM > $0 \%$ MOLM, 10\% MOLM). The shank length was not significantly ( $p>0.05$ ) different between the dietary groups at age 7 weeks. The thigh length of pullets fed $5 \%$ MOLM was significantly $(p<0.05)$ higher at week 1 ( $5 \%$ MOLM $>0 \%$ MOLM, $10 \%$ MOLM). Thigh length of pullets fed $5 \%$ MOLM was significantly $(p<0.05)$ higher than observed for other groups at age 4 weeks ( $5 \%$ MOLM $>0 \%$ MOLM $>10 \%$ MOLM). Thigh length was not significantly $(p>0.05)$ different between the dietary groups at week 7 . The drumstick length of pullets fed 10\% MOLM was significantly $(p<0.05)$ lower at week 1 ( $0 \%$ MOLM, 5\% MOLM > 10\% MOLM). At week 4 , the drumstick length was significantly $(p<0.05)$ different between the dietary groups; pullets fed $5 \%$ MOLM had the highest drumstick length while the lowest was observed in the $10 \%$ MOLM dietary group. The drumstick length was not significantly $(p>0.05)$ different between the dietary groups at 7 week age.

\section{DISCUSSION}

The proximate composition of the four diets administered to chickens over the course of the present experiment (0\% MOLM; $5 \%$ MOLM, and; 10\% MOLM) showed that the Crude Protein, Ash, Ether Extract and Crude Fibre increased as the inclusion of Moringa Oleifera increased. This agrees with the results obtained by Ayssiwede et al. (2011), in which the Crude Protein, Ether Extract, Crude Fibre, and Ash increased as the inclusion of MOLM increased in the diet. However, the results obtained here were in contrast with those of Tesfaye et al. (2012) in which the crude protein content of the control diet was higher than levels in the 5\% MOLM diet, and the ash content decreased as the level of MOLM increased, although, the crude fibre and ether extract increased as the level of MOLM inclusion increased in the diet.

The body weight results obtained here, in which at age 4 weeks, the body weight of broilers fed $0 \%$ MOLM was highest while the lowest body weight was observed in broilers fed 5\% MOLM ( $0 \%$ MOLM $>10 \%$ MOLM $>5 \%$ MOLM) agree with those of Zanu et al. (2012) that showed that increasing levels of MOLM (5\%, 10\%, $15 \%$ ) in the diet of 2 week old broilers fed MOLM for 6 weeks reduced final weight and weight gain, though they observed no significant effect of MOLM on weight gain at $5 \%$ and $10 \%$ inclusion levels. Tesfaye et al. (2012) also observed a similar trend in birds fed MOLM for a longer period. They fed Hubbard Classic broilers MOLM from day old to 7 weeks age and observed that weight at 7 weeks decreased as dietary level of MOLM increased from $0 \%$, through $5 \%$, and $10 \%$ to $20 \%$ levels. The effects observed by Zanu et al. (2012) and Tesfaye et al. (2012) though similar to those observed here, pertain to birds of different age, and/or genotype, and/or time of initiating MOLM feeding, and/or duration of MOLM feeding, and the present study therefore extends the body of existing evidence. In contrast to the present study and those of 
Zanu et al. (2012), recent studies in broilers by Onu and Aniebo (2011) in which one week old Anak broilers were with fed MOLM at $0,2.5,5$, and $7.5 \%$ to 5 weeks age showed that Birds fed with MOLM gained significantly $(P<0.05)$ higher weight and showed superior feed conversion ratio than birds fed the control diet. The contrast of their results from those reported here and other studies (Zanu et al., 2012; Tesfaye et al., 2012) may be explained by inter-study differences in the genotypes examined, time of initiation, and duration of MOLM feeding, and/or other as yet unidentified factors.

Unlike the results observed here in which MOLM dietary inclusion had no significant effect on body weights of pullets at $0-4$ weeks $(p>0.05$ ), although, body weight declined with increasing inclusion of MOLM in the diets, Ashong and Brown (2011) showed that Moringa inclusion in the diet of White Leghorn chicks at higher levels (10\%,20\%, and 30\% levels) between 1 and 6 weeks of age reduced feed intake and weight gain, though post mortem examination showed no signs of toxicity and Moringa was therefore considered safe at the levels examined. The contrast between outcomes of the current study and those of Ashong and Brown (2011) may be explained by differences in the age at initiation and duration of MOLM feeding, the levels of MOLM inclusion, and genetic background of the chickens studied.

The protocol adopted in the present (effect of early feeding on later performance) differs from those in published literature, and the outcomes are therefore instructive in addition to their extension of the existing body of literature on the value and use of MOLM in the diet of young chickens. One important difference between the present study and previous works (Ashong and Brown, 2011; Zanu et al., 2012; Onu and Aniebo, 2011, and; Tesfaye et al., 2012) is that MOLM as used in the present study likely contributed to (and possibly determined) the gut environment during the critical early stage (age 17 days) of the establishment of gut microflora profiles and their attendant effects on gut development in the young chick; since MOLM was fed from day old, rather than at/or after age 1 week as fed by others (Ashong and Brown, 2011; Zanu et al., 2012; Onu and Aniebo, 2011, and; Tesfaye et al., 2012). Further, the contemporaneous nature of studies on animals of different genotype in the present study permits clear comparative inference (and elimination of seasonal and other confounding effects) on the differential effects of genotype on the response of chickens to graded dietary levels of MOLM.

\section{CONCLUSION}

The results of the current study showed that the inclusion of MOLM from age 0-4 weeks in the diet of broilers did not have a positive effect on performance as measured by body weight and coordinated changes in linear growth to aage 4 weeks. These results also showed that the effects of MOLM in early nutrition ( 04 weeks age) are not eliminated by discontinuation of MOLM in the diet from 47 weeks age in as much as at 7 weeks age, birds which were fed a standard diet from age 17 weeks(0\% MOLM) still performed better than birds that had received Moringa at $5 \%$ and 10\% levels from 14 weeks). In contrast to broilers, inclusion of MOLM in the diet of pullets did not have a negative effect on performance (as measured by body weight); this shows that the inclusion of graded levels of MOLM up to 10\% does not have any deleterious effect on the performance of pullets and should be encouraged.

These results therefore highlighted differential adaptation of chickens from different genetic backgrounds (meat vs. egg type breeds) to MOLM. Further studies would examine the effect of early nutrition (through feeding chicks from age 14 weeks with MOLM) on adult laying performance in (Bovans Nera Black Rock) chickens.

The BMI data suggest a beneficial effect of MOLM in reducing fatness in broilers at age 4 weeks, though the benefit disappeared after discontinuation of Moringa feeding. Longer term feeding of Moringa to 
broilers up to market weight or feeding at finisher stage should be explored to examine whether and to what extent the BMI modulating effects of MOLM observed here can be demonstrated (at later age) and harnessed to produce healthier meat for human consumption.

\section{ACKNOWLEDGEMENTS}

The Authors thank The Causal Genetics Institute(TCGI) UK for enabling the existing work through material and personnel support.

\section{REFERENCES}

Ashong J.O. and Dan L. Brown. D.L. (2011) "Safety and efficacy of Moringa oleifera powder for growing poultry". J. Anim. Sci. 89: 84. E-Supplement 1. Abstract retrieved 4" June 2012 from (http://www.jtmtg.org/2011/abstracts/0082.PDF).

Aihonsu J. O. Y. and Sunmola M. A. (1999). "Optimal laying period for profitable and sustainable egg production. Ife" J. of Agric., 20:67-80.

Association of Official Analytical Chemists (A.O.A.C., 1990). Methods of Analysis AOAC Volume 15, Issues 1 - 2

Ayssiwede S.B. ,Dieng A. , Bello H., Chrysostome C.A.A.M. and Hane M.B. (2011). "Effects of Moringa oleifera (Lam.) Leaves Meal Incorporation in Diets on Growth Performances, Carcass Characteristics and Economics Results of Growing Indigenous Senegal Chickens". Pakistan Journal of Nutrition 10 (12): 1132-1145.

Kakengi A.M.V., Kaijage J.T., Sarwatt S.V., Mutayoba S.K., Shem M.N. and Fujihara T. (2007). Effect of Moringa oleifera leaf meal as a substitute for sunflower seed meal on performance of laying hens in Tanzania.

Maciejowski J., Zieba J. (1982). Genetics and animal breeding; ISBN 0444417036, 9780444997326.

Makkar H. P. S. and Becker K. (1996). "Nutritional value and nutritional components of whole and extracted Moringa oleifera leaves". Animal Feed Science and Technology 63, 211228.

Makkar H. P. S. and Becker K. (1997). "Nutrient and anti quality factors on different morphological parts of the Moringa tree". Journal of Agricultural Science 128: 31.

Olugbemi T.S., Mutayoba S.K. and Lekule F.P. (2010a). Moringa oleifera leaf meal as a hypocholesterolemic agent in laying hen diets. Livestock Research for rural development.

Olugbemi T.S., Mutayoba S.K and Lekule F.P. (2010b). "Effect of Moringa (Moringaoleifera) inclusion in cassava based diets fed to broiler chickens". International Journal of Poultry Science 9: 363367.

Oluwafemi, R. A. (2009). "Palm kernel Cake (PKC) utilization in Monogastric Animal Feeding Implications for Sustainable livestock Development". The Internet Journal of Veterinary Medicine, 6(2). DOI: 10.5580/888.

Onu P. N. I. and Aniebo A. O. (2011). "Influence of Moringa oleifera leaf meal on the performance and blood chemistry of starter broilers". International Journal of Food, Agriculture and Veterinary Science, 1 (1): 38-44. 
Szebiotko K. (1981). Utilization of agro-industrial by-products and crop residues by monogastric species in Europe.Presented at the FAO/ILCA workshop on utilization of agro-industrial by-products and crop residues in animal feeding. Dakar, Senegal. 21-25 September .

Tesfaye E., Getachew A., Mengistu U. and Tadelle D. (2012). "Effect of Replacing Moringa Olifera Leaf Meal for Soybean Meal in Broiler Ration". Global Journal of Science Frontier Research Agriculture and Biology, 12(5):1-6.

Zanu H.K., Asiedu P., Tampuori M., Abada M., and Asante I. (2012). "Possibilities of using Moringa (Moringa oleifera) leaf meal as a partial substitute for fishmeal in broiler chicken diets". Online Journal of Animal and Feed Research, 2 (1): 70-75. 
Table 1: Composition of Dietary Treatments as Determined by Proximate Analysis.

\begin{tabular}{|lr|r|r|}
\cline { 2 - 4 } \multicolumn{1}{c|}{} & \multicolumn{2}{l|}{ DIET } & 10\% MOLM \\
\hline Component & 0\% MOLM & 5\% MOLM & 9.00 \\
\hline Ether Extract (\%) & 6.00 & 8.50 & 10.16 \\
Ash (\%) & 9.09 & 9.78 & 7.20 \\
Moisture Content (\%) & 7.20 & 6.20 & 92.20 \\
Dry Matter (\%) & 92.80 & 93.80 & 2.78 \\
Crude Fibre (\%) & 2.51 & 2.60 & 22.92 \\
Crude Protein (\%) & 21.86 & 22.05 &
\end{tabular}

Table 2: Changes in Body Weight and Body Mass Index in Broilers Fed Graded Levels of Dietary Moringa oleifera Leaf Meal

\begin{tabular}{|l|l|l|l|l|}
\cline { 3 - 5 } \multicolumn{2}{c|}{} & \multicolumn{3}{l|}{ Moringa Inclusion } \\
\hline Sn & Trait & 0\% MOLM & $5 \%$ MOLM & $10 \%$ MOLM \\
\hline 1 & Body weight Week 1 (g) & $70.09 \pm 3.59(8) \mathrm{b}$ & $57.8 \pm 3.36(7) \mathrm{a}$ & $66.16 \pm 2.69(8) \mathrm{ab}$ \\
\hline 2 & Body weight Week 4 (g) & $149.93 \pm 8.03(6) \mathrm{b}$ & $78.4 \pm 5.75(3) \mathrm{a}$ & $118.1 \pm 11.06(6) \mathrm{b}$ \\
\hline 3 & Body weight Week 7 (g) & $848.37 \pm 50.17(6) \mathrm{b}$ & $606.63 \pm 117.48(3) \mathrm{a}$ & $502.1 \pm 84.92(5) \mathrm{a}$ \\
\hline 4 & Body weight Rate - Week 1t04 (\%) & $67.61 \pm 3.01(6) \mathrm{b}$ & $28.96 \pm 4.95(3) \mathrm{a}$ & $51.65 \pm 9.12(6) \mathrm{b}$ \\
\hline 5 & Body weight Rate - Week 4t07 (\%) & $139.62 \pm 2.23(6) \mathrm{ab}$ & $151.62 \pm 7.55(3) \mathrm{b}$ & $112.85 \pm 16.85(5) \mathrm{a}$ \\
\hline 6 & Body weight Rate - Week 1t07 (\%) & $167.62 \pm 1.5(6) \mathrm{b}$ & $162.95 \pm 4.9(3) \mathrm{ab}$ & $147.92 \pm 6.68(5) \mathrm{a}$ \\
\hline 7 & Body Mass Index Week 1 & $0.46 \pm 0.03(8)$ & $0.41 \pm 0.03(7)$ & $0.46 \pm 0.02(8)$ \\
\hline 8 & Body Mass Index Week 4 & $0.47 \pm 0.01(6) \mathrm{b}$ & $0.39 \pm 0.02(3) \mathrm{a}$ & $0.42 \pm 0.02(6) \mathrm{ab}$ \\
\hline 9 & Body Mass Index Week 7 & $1.03 \pm 0.04(6) \mathrm{a}$ & $1.36 \pm 0.08(3) \mathrm{b}$ & $0.87 \pm 0.05(5) \mathrm{a}$ \\
\hline
\end{tabular}

The number of birds in each group is indicated in parenthesis.

a.,c, Means with different superscripts on the same row differ significantly $(p<0.05) ; 0 \%, 5 \%, 10 \%$ are the levels of Moringa oleifera inclusion in the diet. Sn: Serial Number. The number of birds in each group is indicated in parenthesis. 
Table 3: Least Squares Means and Standard Errors of Body Weight, Body Weight Rate, and Body Mass Index in Pullets Fed Graded Levels of Dietary MOLM.

\begin{tabular}{|l|l|l|l|l|}
\cline { 3 - 5 } \multicolumn{2}{l|}{} & \multicolumn{3}{l|}{ Moringa Inclusion } \\
\hline Sn & Trait & $\begin{array}{l}\text { 0\% MOLM } \\
\text { (Diet A ) }\end{array}$ & $\begin{array}{l}\text { 5\% MOLM } \\
\text { (Diet B) }\end{array}$ & $\begin{array}{l}\text { 10\% MOLM } \\
\text { (Diet C) }\end{array}$ \\
\hline 1 & Body weight Week 1 (g) & $53.55 \pm 2.62(8) \mathrm{b}$ & $43.89 \pm 2.59(8) \mathrm{a}$ & $42.58 \pm 1.85(6) \mathrm{a}$ \\
\hline 2 & Body weight Week 4 (g) & $69.17 \pm 5.89(7)$ & $75.42 \pm 5.43(6)$ & $60.25 \pm 3.88(6)$ \\
\hline 3 & Body weight Week 7 (g) & $227.4 \pm 35.22(6)$ & $201.65 \pm 23.57(6)$ & $185.63 \pm 12.62(6)$ \\
\hline 4 & Body weight Rate - Week 1 to 4 (\%) & $24.62 \pm 7.94(7)$ & $44 \pm 5.41(6)$ & $33.7 \pm 6.13(6)$ \\
\hline 5 & Body weight Rate - Week 4 to 7 (\%) & $103.5 \pm 7.51(6)$ & $87.11 \pm 13.31(6)$ & $101.23 \pm 6.32(6)$ \\
\hline 6 & Body weight Rate - Week 1 to 7 (\%) & $117.38 \pm 9.53(6)$ & $120.23 \pm 7.52(6)$ & $124.27 \pm 5.29(6)$ \\
\hline 7 & Body Mass Index Week 1 & $0.37 \pm 0.01(8) \mathrm{a}$ & $0.36 \pm 0.02(8) \mathrm{a}$ & $0.62 \pm 0.05(6) \mathrm{b}$ \\
\hline 8 & Body Mass Index Week 4 & $0.31 \pm 0.01(7) \mathrm{a}$ & $0.31 \pm 0.01(6) \mathrm{a}$ & $0.36 \pm 0.01(6) \mathrm{b}$ \\
\hline 9 & Body Mass Index Week 7 & $0.48 \pm 0.03(6)$ & $0.54 \pm 0.02(6)$ & $0.56 \pm 0.03(6)$ \\
\hline
\end{tabular}

${ }_{a, b, c}$ Means with different superscripts on the same row differ significantly $(p<0.05) ; 0 \%, 5 \%, 10 \%$ are the levels of Moringa oleifera inclusion in the diet. The number of birds in each group is indicated in parenthesis. 
Table 4: Least Squares Means and Standard Errors of Linear Growth Traits in Broilers Fed Graded Levels of MOLM

\begin{tabular}{|c|c|c|c|c|}
\hline \multirow[b]{2}{*}{ Sn } & \multirow[b]{2}{*}{ Trait } & \multicolumn{3}{|l|}{ Moringa Inclusion } \\
\hline & & $0 \%$ MOLM & $5 \%$ MOLM & $10 \%$ MOLM \\
\hline 1 & Body length Week 1 (cm) & $12.38 \pm 0.26(8)$ & $11.87 \pm 0.34(7)$ & $12.03 \pm 0.31(8)$ \\
\hline 2 & Body length Week 4 (cm) & $17.83 \pm 0.25(6) c$ & $14.13 \pm 0.27(3) \mathrm{a}$ & $16.58 \pm 0.35(6) b$ \\
\hline 3 & Body length Week 7 (cm) & $28.7 \pm 0.31(6) b$ & $20.83 \pm 1.62(3) a$ & $23.6 \pm 1.77(5) \mathrm{a}$ \\
\hline 4 & Body Girth Week 1 (cm) & $9.63 \pm 0.39(8)$ & $9.03 \pm 0.39(7)$ & $8.96 \pm 0.1(8)$ \\
\hline 5 & Body Girth Week 4 (cm) & $14.17 \pm 0.22(6) b$ & $11.43 \pm 1.6(3) \mathrm{a}$ & $11.97 \pm 0.64(6) a b$ \\
\hline 6 & Body Girth Week 7 (cm) & $24.18 \pm 0.71(6) c$ & $15.9 \pm 0.56(3) a$ & $20.54 \pm 1.47(5) b$ \\
\hline 7 & Shank Length Week 1 (cm) & $1.24 \pm 0.02(8)$ & $1.21 \pm 0.06(7)$ & $1.23 \pm 0.03(8)$ \\
\hline 8 & Shank Length Week 4 (cm) & $2.2 \pm 0.07(6) b$ & $1.57 \pm 0.03(3) a$ & $1.72 \pm 0.03(6) \mathrm{a}$ \\
\hline 9 & Shank Length Week 7 (cm) & $3.93 \pm 0.1(6) b$ & $3.27 \pm 0.19(3) a$ & $3.64 \pm 0.21(5) a b$ \\
\hline 10 & Thigh Length Week 1 (cm) & $2.84 \pm 0.09(8) a b$ & $2.97 \pm 0.18(7) b$ & $2.45 \pm 0.18(8) a$ \\
\hline 11 & Thigh Length Week 4 (cm) & $4.08 \pm 0.14(6) b$ & $3.33 \pm 0.03(3) a$ & $3.67 \pm 0.07(6) a$ \\
\hline 12 & Thigh Length Week 7 (cm) & $8.5 \pm 0.2(6)$ & $6.9 \pm 0.46(3)$ & $6.92 \pm 0.72(5)$ \\
\hline 13 & Drumstick length Week 1 (cm) & $4.25 \pm 0.15(8)$ & $4.19 \pm 0.09(7)$ & $4.29 \pm 0.08(8)$ \\
\hline 14 & Drumstick length Week 4 (cm) & $5.67 \pm 0.34(6) b$ & $4.37 \pm 0.07(3) a$ & $4.7 \pm 0.07(6) a$ \\
\hline 15 & Drumstick length Week 7 (cm) & $10.6 \pm 0.54(6) b$ & $8.47 \pm 0.49(3) a$ & $8.2 \pm 0.56(5) a$ \\
\hline
\end{tabular}

$a, b, c$ Means with different superscripts on the same row differ significantly $(p<0.05) ; 0 \%, 5 \%, 10 \%$ are the levels of Moringa oleifera inclusion in the diet. The number of birds in each group is indicated in parenthesis. 
Table 5: Least Squares Means and Standard Errors of Linear Growth Traits in Pullets Fed Graded Levels of MOLM

\begin{tabular}{|c|c|c|c|c|}
\hline \multirow[b]{2}{*}{ Sn } & \multirow[b]{2}{*}{ Trait } & \multicolumn{3}{|l|}{ Moringa inclusion } \\
\hline & & 0\% MOLM(Diet A) & 5\% MOLM (Diet B) & 10\% MOLM (Diet C) \\
\hline 1 & Body length Week 1 (cm) & $11.98 \pm 0.2(8) c$ & $11.05 \pm 0.32(8) b$ & $8.37 \pm 0.32(6) a$ \\
\hline 2 & Body length Week 4 (cm) & $14.79 \pm 0.5(7) b$ & $15.7 \pm 0.39(6) b$ & $12.97 \pm 0.31(6) \mathrm{a}$ \\
\hline 3 & Body length Week 7 (cm) & $21.42 \pm 1.32(6)$ & $19.13 \pm 1.14(6)$ & $18.23 \pm 0.53(6)$ \\
\hline 4 & Body Girth Week 1 (cm) & $8.75 \pm 0.31(8) b$ & $8 \pm 0.29(8) a b$ & $7.6 \pm 0.33(6) \mathrm{a}$ \\
\hline 5 & Body Girth Week 4 (cm) & $9.7 \pm 0.37(7) a$ & $10.8 \pm 0.31(6) b$ & $8.98 \pm 0.14(6) a$ \\
\hline 6 & Body Girth Week 7 (cm) & $15.4 \pm 1.2(6)$ & $14.53 \pm 0.9(6)$ & $14.15 \pm 0.67(6)$ \\
\hline 7 & Shank length Week 1 (cm) & $1.09 \pm 0.02(8) a b$ & $1.2 \pm 0.05(8) b$ & $0.98 \pm 0.04(6) \mathrm{a}$ \\
\hline 8 & Shank length Week 4 (cm) & $1.39 \pm 0.03(7) a$ & $1.52 \pm 0.06(6) b$ & $1.37 \pm 0.04(6) \mathrm{a}$ \\
\hline 9 & Shank length Week 7 (cm) & $3.45 \pm 0.23(6)$ & $3 \pm 0.14(6)$ & $2.83 \pm 0.14(6)$ \\
\hline 10 & Thigh length Week 1 (cm) & $1.73 \pm 0.07(8) a$ & $2.69 \pm 0.08(8) b$ & $1.77 \pm 0.04(6) \mathrm{a}$ \\
\hline 11 & Thigh length Week 4 (cm) & $3.17 \pm 0.1(7) b$ & $3.85 \pm 0.06(6) c$ & $2.38 \pm 0.05(6) \mathrm{a}$ \\
\hline 12 & Thigh length Week 7 (cm) & $5.08 \pm 0.31(6)$ & $5.32 \pm 0.13(6)$ & $5.07 \pm 0.23(6)$ \\
\hline 13 & Drumstick length Week 1 (cm) & $3.95 \pm 0.15(8) b$ & $3.85 \pm 0.09(8) b$ & $1.85 \pm 0.08(6) \mathrm{a}$ \\
\hline 14 & Drumstick length Week 4 (cm) & $4.23 \pm 0.14(7) b$ & $5.58 \pm 0.11(6) c$ & $3.22 \pm 0.08(6) \mathrm{a}$ \\
\hline 15 & Drumstick length Week 7 (cm) & $7.58 \pm 0.66(6)$ & $7.47 \pm 0.34(6)$ & $6.08 \pm 0.43(5)$ \\
\hline
\end{tabular}

a.,bc Means with different superscripts on the same row differ significantly $(p<0.05) ; 0 \%, 5 \%, 10 \%$ are the levels of Moringa oleifera inclusion in the diet. The number of birds in each group is indicated in parenthesis. 